\title{
Medical Reasons for Marijuana Use, Forms of Use, and Patient Perception of Physician Attitudes Among the US Population
}

\author{
Patrick M. Azcarate, $M D^{1,2,3}$, Alysandra J. Zhang, BA ${ }^{4,5,6}$, \\ Salomeh Keyhani, MD MPH ${ }^{1,4,5,6}$, Stacey Steigerwald, MSSA ${ }^{4,6}$, \\ Julie H. Ishida, MD, MAS, MPH ${ }^{7,8}$, and Beth E. Cohen, MD MAS
}

\begin{abstract}
'Department of Internal Medicine, University of California, San Francisco, San Francisco, CA, USA; ${ }^{2}$ Division of General Internal Medicine, University of California San Francisco, San Francisco, CA, USA; ${ }^{3}$ Cardiovascular Medicine, University of California San Diego, San Diego, USA; ${ }^{4}$ Northern California Institute for Education and Research, San Francisco VA Medical Center, San Francisco, CA, USA; ${ }^{5}$ Department of Medicine, UCSF Division of General Internal Medicine, San Francisco VA Medical Center, San Francisco, CA, USA; ${ }^{6}$ San Francisco Veterans Affairs Medical Center, San Francisco, CA, USA; ${ }^{7}$ Department of Medicine, UCSF Division of Nephrology, San Francisco VA Medical Center, San Francisco, CA, USA;

${ }^{8}$ Department of Nephrology, University of California, San Francisco, San Francisco, CA, USA.
\end{abstract}

BACKGROUND: The use of marijuana for medical purposes is increasing in parallel with expanding legalization and decreased public perception of harm. Despite this increase in use, it is unclear which medical conditions patients are attempting to treat with marijuana and whether they are communicating with medical providers about their use.

OBJECTIVE: To understand the medical reasons for marijuana use, forms of marijuana used for medical purposes, and disclosure of use to physicians.

DESIGN: National, probability-based online survey.

SETTING: The USA, 2017.

PARTICIPANTS: 16,280 US adults.

MAIN MEASURE: Proportion of US adults who agreed with a statement.

KEY RESULTS: A total of 9003 participants completed the survey ( $55 \%$ response rate). Five hundred ninety-one (7\% of US adults) reported using marijuana for medical purposes. The most common medical reasons for marijuana use were anxiety (49\%), insomnia (47\%), chronic pain $(42 \%)$, and depression (39\%). The most common forms of use for all medical conditions were smoking and edibles, followed by vaping, concentrate, and topical. We found women were more likely to use marijuana for posttraumatic stress disorder, sleep, anxiety, and migraines. We did not find substantial variation in medical reasons for marijuana use by race. Among those using marijuana for medical purposes, $21 \%$ did not have a doctor. Among those with doctors, 33\% did not inform them, 28\% reported their doctor was neutral on their use, $32 \%$ reported their doctor was supportive, and 8\% reported their doctor was not supportive. Those who lived in states where medical marijuana was illegal were less likely to disclose use to their doctor.

Electronic supplementary material The online version of this article (https://doi.org/10.1007/s11606-020-05800-7) contains supplementary material which is available to authorized users

Received November 6, 2019

Accepted March 12, 2020

Published online April 6, 2020
LIMITATION: The online format of the survey may have caused selection bias. Wording of the questions may have affected interpretation. Doctors were not queried directly, rather participants were asked about their perception of doctor attitudes.

CONCLUSION: Americans are using marijuana to treat medical conditions despite lack of evidence of efficacy.

KEY WORDS: medical marijuana; cannabis; chronic pain; depression; anxiety.

J Gen Intern Med 35(7):1979-86

DOI: $10.1007 / \mathrm{s} 11606-020-05800-7$

(c) Society of General Internal Medicine 2020

\section{INTRODUCTION}

Marijuana use is legal for medical and/or recreational purposes in thirty-three states, including the District of Columbia. ${ }^{1}$ Use of marijuana has steadily increased along with growing availability through legalization. The National Survey on Drug Use and Health (NSDUH) found past-year marijuana use among US adults doubled over the last decade, rising to $13.3 \%$ in $2014 .^{2}$ Of those who used marijuana in the last year, $90.2 \%$ reported recreational use only, $6.2 \%$ reported medical use only, and $3.6 \%$ reported use for both purposes. ${ }^{3}$ However, commercialization of marijuana along with direct to consumer advertising in recreational dispensaries, on the internet, and through social media allows self-medication without the involvement of healthcare professionals. In addition, the increasing rate of marijuana use has been paralleled by a decreasing perception of harm. Therefore, many Americans may be using marijuana for reasons not supported by evidence. ${ }^{4}$

The evidence base supporting use of marijuana to treat medical conditions is limited. Chronic pain has been more widely studied than other conditions, with most trials focusing on neuropathic pain. ${ }^{5,6}$ While many of these trials demonstrated benefits in reducing pain, most used pharmaceutical cannabis extracts not available in the USA or federally 
available research-grade marijuana that differ considerably from products used by consumers. Therefore, a recent review by the National Academy of Sciences concluded that more evidence is needed to explore the proper forms, routes, and dosages of marijuana for use in chronic pain. ${ }^{6}$ Other studies have demonstrated that cannabis oils may improve the pain and spasticity associated with multiple sclerosis. ${ }^{7}$ There is also evidence marijuana may be useful in treating nausea and vomiting associated with cancer and a recent trial demonstrated that cannabidiol is effective in the treatment of refractory epilepsy of childhood. ${ }^{8,9}$ However, the effectiveness of marijuana in the treatment of insomnia, anxiety, PTSD, and mood disorders has not been established. ${ }^{10,11}$ Despite this lack of evidence, the internet is inundated with articles suggesting marijuana is beneficial in the treatment of these and many other conditions.

Despite the limited evidence, patients with medical conditions are using marijuana and, per results of a 2016-2017 national survey, are doing so significantly more than patients without medical conditions. ${ }^{12}$ Several small qualitative studies have evaluated patient-reported reasons for using marijuana to treat medical conditions, but these have typically focused on specific clinical populations and have relied on convenience samples. ${ }^{13-15}$ One of the largest surveys included 1746 participants from nine medical marijuana clinics in California and found that the most common reasons for use were pain, insomnia, and anxiety. ${ }^{16}$ Reasons for use may also vary by race and gender but this has not been established as women and non-white participants have been underrepresented in prior studies. ${ }^{17}$ An analysis of the 2013 NSDUH data showed no difference between medical and recreational users in terms of race or gender, but reasons for use were not evaluated. ${ }^{18}$

Additionally, little is known about the forms of marijuana patients are using for medical conditions. Pacula and colleagues surveyed 2009 individuals from Oregon, Washington, and Colorado and determined that those using marijuana for medical purposes were more likely to vape and consume edibles compared to those using marijuana for recreational purposes. ${ }^{19}$ This is important because methods of use, such as smoking versus topical application, may have different risks. Finally, understanding how patients and providers communicate about the use of marijuana for medical purposes is essential as healthcare organizations and societies attempt to develop guidelines for prescribing and shared decision-making. Yet, no studies have examined how often patients disclose marijuana use to their providers or whether they perceive their providers as supportive of use.

To address these gaps in knowledge, we conducted a population-based national US survey to assess patientreported medical reasons for marijuana use, forms of marijuana use, patient disclosure to physicians, and their perception of physician support of use. Knowledge about the symptoms and illnesses patients are attempting to treat with marijuana is needed to guide scientific research and public policy.

\section{METHODS}

We developed our survey to assess perceived risks and benefits of marijuana use in addition to exploring patterns of medical marijuana use. To develop survey questions, we reviewed federal surveys, peer-reviewed literature, and media reports ${ }^{4,20-23}$ and interviewed professionals in various fields. We also collected medical reasons for use approved by states with legal medical marijuana. We asked participants who reported using marijuana in the last year, "Did you use marijuana medically, recreationally, or both?" We did not ask whether medical use involved a prescription or formal recommendation from a healthcare professional because, as noted above, increasing availability allows many patients to selftreat for medical conditions. For those reporting medical use, we asked them to select medical reason(s) for use from a list of 14 items and included a text response option for reasons that were not listed (Appendix Table 6). We asked about forms of marijuana use, including smoking, vaporizing, edibles, concentrates, and topicals.

We also included questions on the patients' disclosure of marijuana use to their doctors and whether they believed they were supportive or not. We asked "Which of the following best applies to you?" and the available responses were either "I don't see a doctor," "my doctor is supportive/approves," "my doctor is not supportive/does not approve," "my doctor is neutral," or "my doctor does not know" about my marijuana use (Appendix Table 6). Survey items and content were written at an eighth-grade level and tested with online software. ${ }^{1}$ For further review, cognitive testing of the items was done with a convenience sample of 40 adults of different ages and education levels, including people who did and did not use marijuana. Finally, it was proofread by 20 participants to review and refine online administration. In the survey, use of marijuana to treat medical conditions was assessed regardless of whether it was recommended by a physician or legal in the participants' state of residence.

\section{Sampling Strategy}

To survey US adults, we used Growth from Knowledge (GfK, now Ipsos) KnowledgePanel, a probability-based, nationally representative online panel of the civilian, non-institutionalized US population. ${ }^{24}$ KnowledgePanel was formed by randomly sampling addresses to cover 97\% of the US population. Households without internet access are provided a web-enabled device to ensure participation. All panel members are sampled with a known probability of selection; no one can volunteer to participate. Sampled households are invited to join through a series of mailings via a postage-paid envelop, a toll-free hotline, or an online form. Once recruited, adults complete a Core Profile survey and then have the option of participating in additional surveys. For this general population survey, sampling weights were provided by GfK. 


\section{Survey Administration}

The internet survey was launched on 27 September 2017 to 16,280 US adults aged 18 years and older, and data collection was completed on 9 October 2017. Participants received an incentive of 1000 points (the cash-equivalent of \$1) for completing the survey, which is the standard provided by the survey company. Those without an internet connection instead received a web-enabled device with free monthly internet service as described above. The survey was certified as exempt by the Committee of Human Subject Research of the University of California, San Francisco.

\section{Statistical Analysis and Weighting}

The response rate was the ratio of respondents to all participants who received the survey. ${ }^{25}$ GfK provided final survey weights to account for oversampling of California residents and for non-response. Results were weighted using weights provided by GfK to approximate the US population based on age, sex, race, ethnicity, education, household income, home ownership, and metropolitan area. To assess how well our sample of US adults correlated with federally sponsored surveys, we compared the sociodemographic characteristics of our respondents with those of participants in the 2015 NSDUH. ${ }^{4,21}$ Descriptive statistics were calculated for reasons of use, forms of use, disclosure of use to doctors, and support of use. We then analyzed reasons for use by gender and race and disclosure by state legal status. All analyses were performed with Stata version 15. Significance was determined by two-tailed tests with an alpha of 0.05 .

\section{RESULTS}

\section{Characteristics of Participants}

A total of 9003 participants completed the survey (55\% response rate). In the last year, $1.5 \%$ of US adults reported they used marijuana only for medical purposes, $7.5 \%$ used only for recreational purposes, $5.1 \%$ used for both purposes, and $0.5 \%$ used marijuana but did not report reasons for use. Of the participants reporting they used marijuana for medical purposes, $73 \%(n=460)$ resided in states where marijuana is legal for medicinal or recreational purposes. The mean age of respondents using marijuana for medical purposes was 49 . The majority were men $(52 \%)$ and white, non-Hispanic $(61 \%)$. Baseline characteristics of the 2017 GfK respondents were largely similar to those of the 2015 and 2017 NSDUH respondents (Appendix Table 7).

\section{Patient-Reported Medical Reasons for Marijuana Use}

The most common medical reasons for marijuana use were anxiety (49\%), insomnia (47\%), chronic pain $(42 \%)$, and depression (39\%) (Table 1). The most common forms of use
Table 1 Demographics of Respondents Reporting Use of Marijuana for Medical Reasons Compared with NSDUH Respondents Who Used Marijuana in the Past Year

\begin{tabular}{|c|c|c|}
\hline Characteristic & $\begin{array}{l}2017 \text { KPMM users } \\
\text { in past year }(n= \\
591) *\end{array}$ & $\begin{array}{l}\text { 2017 NSDUH } \\
(n=42,554)\end{array}$ \\
\hline \multicolumn{3}{|l|}{ Age } \\
\hline $18-34$ years & $154(38)$ & $22,626(53)$ \\
\hline $35-49$ years & $147(29)$ & $11,214(26)$ \\
\hline $50-64$ years & $178(23)$ & 4997 (12) \\
\hline$\geq 65$ years & $112(10)$ & $3717(9)$ \\
\hline \multicolumn{3}{|l|}{ Gender } \\
\hline Male & $287(52)$ & $19,987(47)$ \\
\hline Female & $304(48)$ & $22,567(53)$ \\
\hline \multicolumn{3}{|l|}{ Race } \\
\hline White & $436(61)$ & $25,870(61)$ \\
\hline Black & $43(14)$ & $5230(12)$ \\
\hline Hispanic & 71 (19) & 7168 (17) \\
\hline Other & $41(6)$ & $4286(10)$ \\
\hline \multicolumn{3}{|l|}{ Highest education level } \\
\hline High school diploma or & $199(52)$ & $16,664(39)$ \\
\hline less & & \\
\hline Some college & $210(28)$ & $14,288(34)$ \\
\hline $\begin{array}{l}\text { Bachelor's degree or } \\
\text { higher }\end{array}$ & $182(20)$ & $11,602(27)$ \\
\hline \multicolumn{3}{|l|}{ Employment status } \\
\hline Working & $338(58)$ & $28,966(68)$ \\
\hline Not working & $253(42)$ & $13,588(32)$ \\
\hline \multicolumn{3}{|l|}{ Household income } \\
\hline$<\$ 20,000$ & $140(23)$ & $8370(20)$ \\
\hline$\$ 20,000-\$ 49,999$ & $170(28)$ & $13,321(31)$ \\
\hline$\$ 50,000-\$ 74,999$ & $106(18)$ & $6704(16)$ \\
\hline$\geq \$ 75,000$ & $175(31)$ & 14,159 \\
\hline \multicolumn{3}{|c|}{ Legalization status in state of residence at time of survey } \\
\hline \multicolumn{3}{|l|}{$\begin{array}{l}\text { Legal (medical or } \\
\text { recreational) }\end{array}$} \\
\hline \multicolumn{3}{|l|}{ Non-legal } \\
\hline \multicolumn{3}{|c|}{ Doctor awareness and attitudes towards marijuana use } \\
\hline Does not have a doctor & \multicolumn{2}{|c|}{$92(21)$} \\
\hline Doctor not aware of use & \multicolumn{2}{|l|}{$165(26)$} \\
\hline $\begin{array}{l}\text { Doctor is aware and is } \\
\text { neutral }\end{array}$ & \multicolumn{2}{|l|}{$148(22)$} \\
\hline Doctor is aware and & \multicolumn{2}{|l|}{$150(25)$} \\
\hline supportive & & \\
\hline $\begin{array}{l}\text { Doctor is aware and not } \\
\text { supportive }\end{array}$ & \multicolumn{2}{|l|}{$33(6)$} \\
\hline \multicolumn{3}{|l|}{ Medical marijuana use } \\
\hline $\begin{array}{l}\text { Both medical and } \\
\text { recreational }\end{array}$ & \multicolumn{2}{|l|}{$440(77)$} \\
\hline Only medical & \multicolumn{2}{|l|}{$151(23)$} \\
\hline \multicolumn{3}{|l|}{ Reasons for use } \\
\hline Anxiety & \multicolumn{2}{|l|}{$228(49)$} \\
\hline Insomnia & $275(47)$ & \\
\hline Chronic pain & $272(42)$ & \\
\hline Depression & $224(39)$ & \\
\hline Mood & $180(32)$ & \\
\hline Arthritis & $161(23)$ & \\
\hline Migraines & $121(21)$ & \\
\hline PTS̆D & $87(15)$ & \\
\hline Cancer symptoms & $34(5)$ & \\
\hline Libido & $28(6)$ & \\
\hline Glaucoma & $24(4)$ & \\
\hline Seizures/epilepsy & $16(3)$ & \\
\hline Multiple sclerosis & $10(2)$ & \\
\hline HIV/AIDS & $4(1)$ & \\
\hline
\end{tabular}

*Numbers are unweighted, and percentages are weighted to approximate the US population. KPMM KnowledgePanel users of medical marijuana, NSDUH National Survey on Drug Use and Health. We used weights provided by GfK to approximate the US population based on sociodemographic factors (e.g., age, gender, race, ethnicity, education, household income, home ownership, and metropolitan area)

for all medical conditions were smoking and edibles, followed by vaping, concentrate, and topical (Table 2). When analyzed 
Table 2 Medical Reasons for Marijuana Use and Forms of Use

\begin{tabular}{|c|c|c|c|c|c|c|}
\hline \multirow[t]{2}{*}{ Reasons for use } & \multicolumn{5}{|c|}{ Forms of marijuana use, $N(\%)$} & \multirow[t]{2}{*}{$>1$ form, $N(\%)$} \\
\hline & Smoking & Edibles & Vaping & Concentrate & Topical & \\
\hline Anxiety & $223(81)$ & $110(34)$ & $68(24)$ & $33(9)$ & $24(7)$ & $111(36)$ \\
\hline Insomnia & $197(77)$ & $116(36)$ & $61(21)$ & $37(10)$ & $31(9)$ & $107(33)$ \\
\hline Chronic pain & $190(78)$ & $107(32)$ & $64(20)$ & $40(11)$ & 41 (12) & $111(34)$ \\
\hline Depression & $181(85)$ & $81(31)$ & $53(21)$ & $26(10)$ & $15(6)$ & $84(35)$ \\
\hline Mood & $146(85)$ & $69(35)$ & $47(22)$ & $23(11)$ & $18(7)$ & $72(35)$ \\
\hline Arthritis & $114(77)$ & $62(35)$ & $31(20)$ & $20(5)$ & 38 (14) & 70 (39) \\
\hline Migraines & $97(85)$ & $47(33)$ & $36(33)$ & $12(7)$ & $11(7)$ & $51(40)$ \\
\hline PTSD & $70(92)$ & $26(18)$ & 17 (13) & $13(7)$ & $9(4)$ & $28(21)$ \\
\hline Cancer symptoms & $20(64)$ & $19(55)$ & $9(22)$ & $5(9)$ & $7(7)$ & $15(34)$ \\
\hline Libido & $22(86)$ & $11(28)$ & $7(23)$ & $2(10)$ & $3(6)$ & $11(33)$ \\
\hline Glaucoma & $20(81)$ & $11(49)$ & $6(29)$ & $3(13)$ & $4(12)$ & $12(45)$ \\
\hline Seizures/epilepsy & $15(97)$ & $3(13)$ & $2(10)$ & $1(4)$ & $1(3)$ & $4(16)$ \\
\hline Multiple sclerosis & $9(96)$ & $2(24)$ & $3(29)$ & $1(13)$ & 0 & $2(24)$ \\
\hline HIV/AIDS & $4(100)$ & $1(24)$ & $1(24)$ & 0 & 0 & $1(24)$ \\
\hline
\end{tabular}

Numbers are unweighted, and percentages are weighted to approximate the US population. We used weights provided by GfK to approximate the US population based on sociodemographic factors (e.g., age, gender, race, ethnicity, education, household income, home ownership, and metropolitan area)

by medical condition, we found that smoking was more common among patients using medical marijuana for PTSD, edibles for cancer-related symptoms, and topical forms for arthritis.

\section{Gender and Racial Differences in Medical Reasons for Marijuana Use}

In analyses comparing medical reasons for marijuana use by gender, we found that women were significantly more likely than men to use marijuana for posttraumatic stress disorder (PTSD), sleep disturbances or insomnia, anxiety, and migraines (Table 3). Men were significantly more likely to use marijuana for mood stabilization. We found no significant differences in medical reasons for marijuana use by race other than more frequent use for HIV in white versus non-white respondents (Table 4).

\section{Rates of Disclosure of Marijuana Use}

Among those using cannabis for medicinal purposes, 21\% reported they did not have a doctor (Appendix Table 8). Among these respondents without a doctor, $(62.9 \%)$ were between ages 18 and 34 and $22 \%$ had a total household income of more than $\$ 75,000$. Fifty-three percent were white. The majority $(62 \%)$ were from states where marijuana was legal. Among those with doctors, $33 \%$ did not inform them of their marijuana use, $28 \%$ reported their doctor was neutral on their use, $32 \%$ reported their doctor was supportive, and $8 \%$ reported their doctor was not supportive (Table 5). Compared to states where medical marijuana was illegal, participants in legal states were more likely to report that their doctor was aware and either neutral or supportive of use (Table 5).

There were no differences in disclosure between men and women (Appendix Table 9). Among those who used medical marijuana, we found that those who were white were less likely to tell their doctors about use than those of other races (Appendix Table 9).

\section{DISCUSSION}

In this nationally representative survey of US adults, we found the most common patient-reported medical reasons for marijuana use were anxiety, insomnia, chronic pain, and depression. Among those using marijuana for medical purposes, the majority informed their doctors and few respondents felt their doctors were not supportive, though patients were less likely to disclose use in states where medical marijuana was illegal.

Our results confirm prior findings in limited populations that chronic pain and mental health symptoms are the most common reasons for medical marijuana use. A 2011 survey of 1655 adults from nine medical marijuana clinics in California found that the main reasons for use reported by patients were pain relief (82.6\%), improved sleep (70.6\%), and relaxation $(55.6 \%) .{ }^{13} \mathrm{~A}$ study of 628 participants recruited from Canadian medical cannabis dispensaries and organizations that assist

Table 3 Medical Reasons for Marijuana Use by Gender

\begin{tabular}{llll}
\hline \hline Reasons for use & $\begin{array}{l}\text { Female, } \boldsymbol{N} \\
(\boldsymbol{\%})\end{array}$ & $\begin{array}{l}\text { Male, } \boldsymbol{N} \\
(\boldsymbol{\%})\end{array}$ & $\begin{array}{l}\boldsymbol{p} \\
\text { value }\end{array}$ \\
\hline Anxiety & $169(57.7)$ & $119(41.3)$ & 0.002 \\
Chronic pain & $132(39.3)$ & $140(45.0)$ & 0.27 \\
Sleep disturbances or & $151(55.2)$ & $114(39.7)$ & 0.004 \\
insomnia & $123(42.4)$ & $101(36.8)$ & 0.29 \\
Depression & $84(25.8)$ & $114(38.1)$ & 0.01 \\
Mood stabilization & $92(25.5)$ & $69(20.6)$ & 0.27 \\
Arthritis & $7(1.90)$ & $101(4.34)$ & 0.14 \\
Seizures/epilepsy & $79(26.7)$ & $10(16.6)$ & 0.02 \\
Migraines & $41(11.3)$ & $28(9.03)$ & 0.45 \\
Other & $58(18.7)$ & $29(10.8)$ & 0.04 \\
PTSD & $24(7.43)$ & $10(2.97)$ & 0.06 \\
Cancer-related symptoms & $12(4.15)$ & $16(7.17)$ & 0.21 \\
Libido & $10(3.62)$ & $14(4.24)$ & 0.77 \\
Glaucoma & $5(1.57)$ & $5(2.13)$ & 0.66 \\
Multiple sclerosis & $1(0.45)$ & $3(1.30)$ & 0.38 \\
HIV/AIDS & &
\end{tabular}

Numbers are unweighted, and percentages are weighted to approximate the US population. We used weights provided by GfK to approximate the US population based on sociodemographic factors (e.g., age, gender, race, ethnicity, education, household income, home ownership, and metropolitan area) 
Table 4 Medical Reasons for Marijuana Use by Race

\begin{tabular}{llll}
\hline \hline Reasons for use & $\begin{array}{l}\text { White, } \boldsymbol{N} \\
(\boldsymbol{\%})\end{array}$ & $\begin{array}{l}\text { Non-white, } \boldsymbol{N} \\
(\boldsymbol{\%})\end{array}$ & $\begin{array}{l}\boldsymbol{p} \\
\text { value }\end{array}$ \\
\hline PTSD & $59(14.2)$ & $28(15.2)$ & 0.80 \\
Sleep disturbances or & $203(47.1)$ & $72(47.0)$ & 0.99 \\
insomnia & $127(34.1)$ & $53(29.3)$ & 0.36 \\
Mood stabilization & $208(52.7)$ & $80(43.3)$ & 0.10 \\
Anxiety & $162(41.4)$ & $62(36.6)$ & 0.37 \\
Depression & $12(3.72)$ & $4(2.30)$ & 0.49 \\
Seizures/epilepsy & $3(1.37)$ & $1(0.13)$ & 0.013 \\
HIV/AIDS & $27(4.91)$ & $7(5.27)$ & 0.89 \\
Cancer-related symptoms & $22(5.88)$ & $6(5.50)$ & 0.90 \\
Libido & $82(21.3)$ & $39(21.3)$ & 0.91 \\
Migraines & $17(3.52)$ & $7(4.62)$ & 0.62 \\
Glaucoma & $121(23.3)$ & $41(22.4)$ & 0.86 \\
Arthritis & $9(2.65)$ & $1(0.60)$ & 0.13 \\
Multiple sclerosis & $209(46.3)$ & $63(35.8)$ & 0.06 \\
Chronic pain & $54(11.5)$ & $15(7.89)$ & 0.26 \\
Other &
\end{tabular}

Numbers are unweighted, and percentages are weighted to approximate the US population. We used weights provided by GfK to approximate the US population based on sociodemographic factors (e.g., age, gender, race, ethnicity, education, household income, home ownership, and metropolitan area)

users for medical marijuana found the most common reasons for use were insomnia (85\%), pain (82\%), anxiety (79\%), and depression $(67 \%) .{ }^{26}$ Finally, in an anonymous online survey of 1429 adults in Washington in 2016, the most common reasons for use were pain $(61.2 \%)$, anxiety $(58.1 \%)$, and depression $(50.3 \%) .{ }^{27}$ In studies with specific populations, such as patients with cancer or HIV, ${ }^{14}$ disease-related concerns (i.e., appetite stimulation) were the most common reasons for use, but use for pain, sleep, and mental health concerns was also frequent.

Our study expands on this important prior work by reporting medical reasons for marijuana use from a nationally representative survey. In our survey, mental health symptoms, including anxiety (49\%) and insomnia (47\%), were more common reasons for use than chronic pain (42\%). This is important to note because while states differ in approved indications for medical marijuana use, nearly all include chronic pain while few include mental health conditions such as anxiety.

Table 5 Doctor Awareness and Attitudes Towards Marijuana Use by State Legalization Status Among Participants with a Doctor

\begin{tabular}{llll}
\hline \hline & $\begin{array}{l}\text { States where } \\
\text { MM is legal, } \boldsymbol{n} \\
(\mathbf{\% )}\end{array}$ & $\begin{array}{l}\text { States where } \\
\text { MM is illegal, } \\
\boldsymbol{n} \mathbf{( \% )}\end{array}$ & Overall \\
\hline $\begin{array}{l}\text { Doctor not aware of } \\
\text { use }\end{array}$ & $121(29)$ & $44(46)$ & $\begin{array}{l}165 \\
(33)\end{array}$ \\
$\begin{array}{l}\text { Doctor is aware and } \\
\text { is neutral }\end{array}$ & $128(30)$ & $20(21)$ & $\begin{array}{l}148 \\
(28)\end{array}$ \\
$\begin{array}{l}\text { Doctor is aware and } \\
\text { supportive of use }\end{array}$ & $130(35)$ & $20(21)$ & $\begin{array}{l}150 \\
(32)\end{array}$ \\
$\begin{array}{l}\text { Doctor is aware and } \\
\text { not supportive of use }\end{array}$ & $23(6)$ & $10(14)$ & $33(8)$ \\
\hline
\end{tabular}

Numbers are unweighted, and percentages are weighted to approximate the US population. We used weights provided by GfK to approximate the US population based on sociodemographic factors (e.g., age, gender, race, ethnicity, education, household income, home ownership, and metropolitan area). $p$ value $=0.001$
While several trials have found evidence that marijuana improves chronic pain, neuropathic pain, and spasticity, little is known about the efficacy, route, and dosages of more commonly available cannabis products. 5,6

Far fewer studies have evaluated the use of marijuana to treat mental health symptoms, and some studies have suggested potential psychological harms. ${ }^{10}$ One multicenter case-control study at 11 sites across Europe and Brazil found that daily cannabis use was associated with increased odds of developing a psychotic disorder. ${ }^{28}$ Another study of 561 people using medical marijuana found they perceived a significant reduction in symptoms of depression, anxiety, and stress after using marijuana but that depressive symptoms actually worsened over time. ${ }^{29}$ These findings highlight the need for more studies to elucidate the potential benefits and harms of marijuana in the treatment of pain, insomnia, and anxiety.

We found the most common forms of marijuana used for medical conditions in the US population were smoking and edibles. Smoking was more common among patients using marijuana for PTSD, edibles for cancer-related symptoms, and topical forms for arthritis. In prior analyses from our survey examining use for medicinal and/or recreational purposes, smoking was also the most prevalent form of use, with $12.9 \%$ of US adults reporting smoking marijuana in the last year. ${ }^{30}$ The fact that smoking is the predominant form of use is concerning given the known adverse effects of particulate matter on health. Pulmonary effects of smoking marijuana include increased cough, wheezing, and sputum production. $^{31-33}$ The effects on pulmonary function and obstructive lung disease are indeterminate due to the low rates of cumulative exposure in many prior studies. ${ }^{33}$ Acute cardiovascular effects of marijuana include tachycardia and orthostatic hypotension. While the evidence base examining the association of marijuana use with cardiovascular events is currently insufficient, $^{34}$ there may be an increased risk of acute coronary syndrome as demonstrated by a study of 3882 adults with an acute myocardial infarction (MI) that showed a 4.8-fold increased risk of MI within an hour of marijuana use. ${ }^{35}$ More research is needed to determine the long-term cardiopulmonary effects of marijuana and whether certain forms, such as edible or topical, would have preferable risk/benefit profiles. $^{33,}, 34$

In our subgroup analysis, we found that women were more likely to use marijuana for PTSD, insomnia, anxiety, and migraines, and men were more likely to use marijuana for mood stabilization. A 2016 online survey of 1418 participants who used marijuana also found differences in reasons for use, with women being significantly more likely than men to report using marijuana to treat anxiety, migraines, nausea, and irritable bowel syndrome. ${ }^{36}$ This prior survey did not specifically inquire about mood symptoms or PTSD. Variations in prevalence of diseases by sex likely play a role in these differences, but it is possible that the efficacy, or perceived efficacy, of marijuana for certain conditions may differ in men and women. Finally, some studies have found sex differences in side 
effect profiles of traditional medications to treat these conditions. For example, antipsychotic medications have been shown to cause greater weight gain and other metabolic problems in women. ${ }^{37}$ This may prompt more women to use marijuana as an alternative to traditional medications.

We did not find significant differences in reasons for use by race, other than for HIV, which was a rare reason for use. As research continues, it will be important to include underrepresented populations as patterns of use for medical purposes may differ by socioeconomic status, race, and access to medical care.

Despite the lack of evidence on the efficacy of marijuana use for health conditions, nearly half of those who disclosed medical marijuana use to their doctors reported they were supportive and only $8 \%$ of patients felt their doctors were not supportive. The overall high perception of support in our survey contrasts several prior physician surveys describing low approval rates of medical marijuana. In 2005, a survey of 960 physicians nationwide found that only $36 \%$ supported legalization of medical marijuana and $26 \%$ were neutral. ${ }^{38} \mathrm{~A}$ 2013 survey of 520 family physicians in Colorado found that, despite medical marijuana being legal, only $19 \%$ of physicians believed they should be able to recommend it and most agreed it posed serious mental and physical health risks. ${ }^{39}$

The report of higher levels of support in our survey could be explained by several factors. We did not query healthcare providers directly but instead asked participants their perception of their healthcare providers' level of support. As such, participants who reported marijuana use to their doctor may have already known they would be supportive. Our data is also more recent compared to the prior surveys, and physicians' attitudes may parallel the decreased perception of harm that has been documented in surveys of the general population. ${ }^{2,4}$ Indeed, a more recent survey of 400 medical oncologists found that $46 \%$ would recommend medical marijuana to their patients and $67 \%$ viewed it as a helpful adjunct to pain management. ${ }^{40}$

We also found that $26 \%$ of those who used marijuana for medical purposes did not inform their doctor and that this rate was higher in states where medical marijuana was illegal. Potential reasons for non-disclosure include mistrust, fear of disapproval or bias, and legal consequences in states where marijuana is illegal. Additionally, it is possible patients did not disclose their use because their doctor did not directly ask them. Given the lack of evidence, training, and guidelines on the use of marijuana for medical purposes, some healthcare providers may feel uncomfortable discussing this with patients. Regardless of the reasons why marijuana use was not disclosed, this demonstrates a concerning lack of communication and missed opportunity for providers to counsel patients about the risks and benefits of marijuana use. Additionally, we found that $21 \%$ of participants using medical marijuana did not have a doctor. The majority $(62.9 \%)$ were between ages 18 and 34 and only $22 \%$ had a total household income of more than $\$ 75,000$. Therefore, while their insurance status is unknown, their young age and lower income may have impacted their decision or ability to see a provider.

Despite the limitations of the evidence, several healthcare institutions and societies have created policies and guidelines for their healthcare workers to have these important conversations. For example, while Veterans Health Administration providers are unable to complete forms referring patients to State-approved marijuana programs, 2017 VA guidelines encourage physicians to discuss marijuana use with patients and explore how its use may be affecting their health. ${ }^{41}$

Though our study benefits from a nationally representative sample, it has several limitations. First, the ordering of the list was not randomized across participants. Also, our results may be more reflective of individuals who are willing to participate in online surveys. However, demographics of our survey respondents were similar to those from prior national studies and there was no evidence of non-response bias on key demographics. ${ }^{42}$ Another limitation is that our survey did not directly address perceived efficacy of marijuana use for medical conditions. It would be helpful to know if patients and their healthcare providers believe marijuana is improving their symptoms. Also, we asked about chronic pain as a general category and not specific subtypes of pain. Finally, we did not survey providers directly, rather, respondents reported their perception of their doctors' views on marijuana and we did not ask about disclosure to other types of healthcare providers.

Despite these limitations, our results demonstrate that US adults are using marijuana to treat conditions where it has not been convincingly shown to provide benefit and highlight the urgent need for higher quality studies on the effectiveness of medical marijuana. They also underscore the need for clinical guidelines to support more complete and informed discussions between patients and providers about medical marijuana use.

Research Statement/Study Protocol:

Study Protocol: Available from Dr. Keyhani (salomeh.keyhani@ucsf.edu).

Data Set: Available upon request from salomeh.keyhani@ucsf.edu.

Statistical Code: Not available.

Corresponding Author: Patrick M. Azcarate, MD; Cardiovascular Medicine University of California San Diego, San Diego, USA (e-mail: pazcarate@ucsd.edu).

Funding Information This research was financially supported in part by the National Heart, Lung, and Blood Institute of the National Institutes of Health under grant number R01HL130484-01A1. Dr. 
Keyhani's administrative funds provided by the Veterans Health Research Institute (NCIRE) also supported this research. Dr. Ishida was supported by a career development award from the National Institute of Diabetes and Digestive and Kidney Diseases (K23DK103963).

\section{Compliance with Ethical Standards}

The survey was certified as exempt by the Committee of Human Subject Research of the University of California, San Francisco.

Conflict of Interest: The authors declare that they do not have a conflict of interest.

Disclaimer: The views expressed in this article are those of the authors and do not represent the views of the VA or the US government.

Role of the Funder/Sponsor: The funder had no role in the design and conduct of the study; collection, management, and analysis of the data; preparation, review, or approval of the manuscript; and decision to submit the manuscript for publication.

\section{REFERENCES}

1. The SMOG Readability Formula 2018 [cited 2018 July 10]. Available from: http://www.readabilityformulas.com/smog-readability-formula. php.

2. Compton WM, Han B, Jones CM. Blanco C. Hughes A. Marijuana use and use disorders in adults in the USA, 2002-14: analysis of annual cross-sectional surveys. Lancet Psychiatry 2016;3(10):954-64. https:// doi.org/10.1016/s2215-0366(16)30208-5.

3. Compton WM, Han B, Hughes A, Jones CM, Blanco C. Use of Marijuana for Medical Purposes Among Adults in the United States. JAMA. 2017;317(2):209-11. https://doi.org/10.1001/jama.2016.18900

4. Keyhani S, Steigerwald S, Ishida J, Vali $\mathbf{M}$, Cerda $\mathbf{M}$, Hasin $\mathbf{D}$, et al Risks and Benefits of Marijuana Use: A National Survey of U.S. Adults. Ann Intern Med. 2018;169(5):282-90. https://doi.org/10.7326/m180810

5. Whiting PF, Wolff RF, Deshpande S, Di Nisio M, Duffy S, Hernandez AV, et al. Cannabinoids for Medical Use: A Systematic Review and Metaanalysis. Jama. 2015;313(24):2456-73. https://doi.org/10.1001/jama. 2015.6358.

6. The health effects of cannabis and cannabinoids: The current state of evidence and recommendations for research. Washington, DC, US National Academies Press; 2017. xviii, 468-xviii, p.

7. Brust J, Fee D, Pushpa Narayanaswami P, Patel A, Song S, Youssof S et al. Position statement: Use of Medical Marijuana for Neurologic Disorders. Am Acad Neurol. 2018.

8. Kramer JL. Medical marijuana for cancer. CA Cancer J Clin 2015;65(2):109-22. https://doi.org/10.3322/caac.21260.

9. O'Connell BK, Gloss D, Devinsky O. Cannabinoids in treatmentresistant epilepsy: A review. Epilepsy Behav. 2017;70(Pt B):341-8. https://doi.org/10.1016/j.yebeh.2016.11.012.

10. Hill KP. Medical Marijuana for Treatment of Chronic Pain and Other Medical and Psychiatric Problems: A Clinical Review. Jama 2015;313(24):2474-83. https://doi.org/10.1001/jama.2015.6199.

11. O'Neil ME, Nugent SM, Morasco BJ, Freeman M, Low A, Kondo $\mathbf{K}$ et al. Benefits and Harms of Plant-Based Cannabis for Posttraumatic Stress Disorder: A Systematic Review. Ann Intern Med 2017;167(5):33240. https://doi.org/10.7326/M17-0477.

12. Dai H, Richter KP. A National Survey of Marijuana Use Among US Adults With Medical Conditions, 2016-2017. JAMA Netw Open. 2019;2(9):e1911936.

13. Nunberg H, Kilmer B, Pacula RL, Burgdorf J. An Analysis of Applicants Presenting to a Medical Marijuana Specialty Practice in California. J Drug Policy Analy. 2011;4(1)

14. Furler MD, Einarson TR, Millson M, Walmsley S, Bendayan R. Medicinal and recreational marijuana use by patients infected with HIV. AIDS Patient Care STDs 2004;18(4):215-28. https://doi.org/10.1089/ 108729104323038892

15. Park JY, Wu LT. Prevalence, reasons, perceived effects, and correlates of medical marijuana use: A review. Drug Alcohol Depend. 2017;177:1-13.
16. Reinarman $\mathbf{C}$, Nunberg $\mathbf{H}$, Lanthier $\mathbf{F}$, Heddleston $\mathbf{T}$. Who are medical marijuana patients? Population characteristics from nine California assessment clinics. J Psychoactive Drugs 2011;43(2):128-35. https:// doi.org/10.1080/02791072.2011.587700.

17. Nugent SM, Kansagara D. The Effects of Cannabis Among Adults With Chronic Pain. Ann Intern Med 2018;168(7):525. https://doi.org/10. 7326/117-0732.

18. Lin LA, Ingen MA, Jannausch M, Bohnert KM. Comparing adults who use cannabis medically with those who use recreationally: Results from a national sample. Addict Behav. 2016;61:99-103.

19. Pacula RL, Jacobson M, Maksabedian EJ. In the weeds: a baseline view of cannabis use among legalizing states and their neighbours. Addiction. 2016;111(6):973-80.

20. Hasin DS. US Epidemiology of Cannabis Use and Associated Problems. Neuropsychopharmacology. 2018;43(1):195-212

21. Cerda M, Wall M, Keyes KM, Galea S, Hasin D. Medical marijuana laws in 50 states: investigating the relationship between state legalization of medical marijuana and marijuana use, abuse and dependence. Drug Alcohol Depend. 2012;120(1-3):22-7.

22. Hasin DS, Grant B. NESARC Findings on Increased Prevalence of Marijuana Use Disorders-Consistent With Other Sources of Information. JAMA Psychiatry. 2016;73(5):532

23. Azofeifa A, Mattson ME, Schauer G, McAfee T, Grant A, Lyerla R. National Estimates of Marijuana Use and Related Indicators - National Survey on Drug Use and Health, United States, 2002-2014. Morb Mortal Wkly Rep Surveill Summ (Washington, DC: 2002). 2016;65(11):1-28

24. GfK. KnowledgePanel 2017 [cited 2017 December 18]. Available from: www.gfk.com/products-a-z/us/knowledgepanel-united-states.

25. Research AAfPO. Standard Definitions: Final Dispositions of Case Codes and Outcome Rates for Surveys. Oakbrook Terrace, IL: AAPOR, 2016.

26. Walsh Z, Callaway R, Belle-Isle L, Capler R, Kay R, Lucas $\mathbf{P}$, et al. Cannabis for therapeutic purposes: Patient characteristics, access, and reasons for use. Int J Drug Policy. 2013;24(6):511-6. https://doi.org/10. 1016/j.drugpo.2013.08.010

27. Sexton M, Cuttler C, Finnell JS, Mischley LK. A Cross-Sectional Survey of Medical Cannabis Users: Patterns of Use and Perceived Efficacy. (2378-8763 (Print)).

28. Di Forti M, Quattrone D, Freeman TP, Tripoli G, Gayer-Anderson C, Quigley $\mathbf{H}$, et al. The contribution of cannabis use to variation in the incidence of psychotic disorder across Europe (EU-GEI): a multicentre case-control study. Lancet Psychiatry 2019;6(5):427-36. https://doi.org/ 10.1016/s2215-0366(19)30048-3.

29. Cuttler C, Spradlin A, McLaughlin RJ. A naturalistic examination of the perceived effects of cannabis on negative affect. J Affect Disord 2018;235:198-205. https://doi.org/10.1016/j.jad.2018.04.054.

30. Steigerwald S, Wong PO, Cohen BE, Ishida JH, Vali M. Madden E, et al. Smoking, Vaping, and Use of Edibles and Other Forms of Marijuana Among U.S. Adults. Ann Intern Med 2018;169(12):890-2. https://doi. org/10.7326/m18-1681.

31. Gates P, Jaffe A, Copeland J. Cannabis smoking and respiratory health: consideration of the literature. Respirology (Carlton, Vic). 2014; 19(5):65562. https://doi.org/10.1111/resp.12298.

32. Tetrault JM, Crothers K, Moore BA, Mehra R, Concato J, Fiellin DA Effects of marijuana smoking on pulmonary function and respiratory complications: a systematic review. Arch Intern Med. 2007:167(3):221-8.

33. Ghasemiesfe M, Ravi D, Vali M, Korenstein D, Arjomandi M, Frank J, et al. Marijuana Use, Respiratory Symptoms, and Pulmonary Function: A Systematic Review and Meta-analysis. Ann Intern Med. 2018;169(2):106-15.

34. Ravi D, Ghasemiesfe M, Korenstein D, Cascino T, Keyhani S Associations Between Marijuana Use and Cardiovascular Risk Factors and Outcomes: A Systematic ReviewMarijuana Use and Cardiovascular Risk Factors and Outcomes. Ann Intern Med 2018;168(3):187-94. https://doi.org/10.7326/m17-1548.

35. Frost L, Mostofsky E, Rosenbloom JI, Mukamal KJ, Mittleman MA. Marijuana use and long-term mortality among survivors of acute myocardial infarction. Am Heart J. 2013;165(2):170-5.

36. Cuttler C, Mischley LK, Sexton M. Sex Differences in Cannabis Use and Effects: A Cross-Sectional Survey of Cannabis Users. Cannabis Cannabinoid Res. 2016;1(1): 166-75.

37. Seeman MV. Secondary effects of antipsychotics: women at greater risk than men. Schizophr Bull. 2009;35(5):937-48.

38. Charuvastra A, Friedmann PD, Stein MD. Physician attitudes regarding the prescription of medical marijuana. J Addict Dis 2005;24(3):87-93. https://doi.org/10.1300/J069v24n03_07. 
39. Kondrad E, Reid A. Colorado family physicians' attitudes toward medical marijuana. J Am Board Fam Med 2013;26(1):52-60. https://doi.org/10. 3122/jabfm.2013.01.120089.

40. Braun IM, Wright A, Peteet J, Meyer FL, Yuppa DP, Bolcic-Jankovic D, et al. Medical Oncologists' Beliefs, Practices, and Knowledge Regarding Marijuana Used Therapeutically: A Nationally Representative Survey Study. (1527-7755 (Electronic)).

41. Clancy CM. Access to VHA clinical programs for veterans participating in state-approved marijuana programs. In: Veterans Health Administration DoVA, editor. Washington, DC 2017.
42. Heeren T, Edwards EM, Dennis JM, Rodkin S, Hingson RW, Rosenbloom DL. A comparison of results from an alcohol survey of a prerecruited Internet panel and the National Epidemiologic Survey on Alcohol and Related Conditions. Alcohol Clin Exp Res 2008;32(2):222-9. https://doi.org/10.1111/j.1530-0277.2007.00571.x.

Publisher's Note Springer Nature remains neutral with regard to jurisdictional claims in published maps and institutional affiliations. 